\title{
International Volunteers as Strangers in Szeklerland
}

\author{
Ágota SILLÓ \\ University of Debrecen, Hungary \\ agotasillo@gmail.com
}

\begin{abstract}
This paper focuses on volunteer tourism, which is approached as a new phenomenon in a Romanian minority region, i.e. Szeklerland. Volunteer tourism has developed very fast in last decades at international level and mostly in the developed societies. As an alternative tourism form, it is very popular among the youth and gap-year students. Volunteer tourism is a kind of international volunteering which offers opportunity for someone to volunteer and travel at the same time in a foreign country. Volunteer tourism makes possible the meeting and collaboration between local community and international volunteers. As a new phenomenon in the case of Szeklerland, volunteer tourism was started here by a foreign person, originated from England, who has established himself in Miercurea Ciuc, Harghita County, Romania. In this region, this event was regarded as a strange action; here, local volunteering is also a new phenomenon. The communist rule had a negative effect on the developing of volunteer culture in Eastern Europe. Therefore, in the $21^{\text {st }}$ century in Romania, volunteering is still a rare phenomenon. On the other hand, the presence of foreign volunteers in Szeklerland is an unusual phenomenon. Volunteer tourists are those who meet with locals and thereby are more close to the local people to whom these people speak in foreign languages, have foreign looks and cultures. Due to their lack of English language skills, local people and organizations do not know how to connect with them. So, international volunteering or volunteer tourism is that phenomenon which allows to meet different foreign cultures, where the common ground could be a commonly spoken language, i.e. the English.
\end{abstract}

Keywords: volunteer tourism, motivations, international volunteers, Szeklerland 


\section{Introduction}

The objective of this paper is to discuss a topic which is essentially a new phenomenon in Romania and in the Szeklerland region as well, i.e. volunteer tourism. Volunteer tourism, or "voluntourism" is a phenomenon which refers to volunteering abroad in a pre-packed excursion form. The participants usually pay a fee to an international or local organization, which will place them on projects based on the preferences of volunteer tourists. The theme of these volunteer tourist projects generally ranges from education to health and human rights and appear in the form of organized trips (Kass 2013).

At aggregate level, volunteer tourism is a phenomenon which, after some researchers, started in the 1950s with the activity of Voluntary Service Overseas. From those times, volunteer tourism passed over a developing process whose result is that "by the beginning of the XXI. century, voluntourism was an established industry, with hundreds of thousands of mostly eighteen to twenty-five year olds embarking on these constructed volunteer vacations" (Kass 2013: 26).

In the last few years in Szeklerland, foreign-looking and foreign-languagespeaking people started to appear - they are international volunteers. Szeklerland, or the Szekler region is a Hungarian-inhabited region situated in eastern Transylvania (Harghita, Covasna, and Mureş counties), Romania. The development of volunteering in Romania has a different path than in western societies. In the developed societies, such as America or Western Europe, volunteering is an older activity than in post-communist countries such as Romania. The communist regime did not favor the incorporation of volunteering (Silló 2016). Nowadays, after the transition period, volunteering is still a missing link in Romania, wherefore in Szeklerland as well (Voicu \& Voicu 2003b). This is also relevant for volunteer tourism.

The objective of this paper is to analyze and present through the case of an organization established by a foreign person in Miercurea Ciuc (Harghita County) the motivation of international volunteers and the reasons why they chose Romania as their placement.

\section{Volunteer tourism trends}

After the 1970s, the financial support of non-governmental organizations has decreased (Chen \& Chen 2011). These organizations had to complete their financial framework, looking for international volunteers who could contribute (Otoo 2013) to the activities of such organizations both financially and physically. The attraction of foreign volunteers can be regarded as an innovative form of civic activism, which can also be considered a form of alternative tourism. 
As an alternative tourism, volunteer tourism established itself as a significant phenomenon for decades, and it has gained various denominations such as "volunteer tourism" (Henderson 1981), "volunteer vacation" (McMillion et al. 2006), "mini-mission" (Brown \& Morrison 2003), "pro-poor tourism” (Ashley et al. 2001, Hall 2007), "vacation volunteering", "altruistic tourism" (Singh 2002), "service-based vacation", "participatory environmental research tourism (PERT)" (Ellis 2003), or "voluntourism" (Chen \& Chen 2011). In my paper, I opted for two terms: volunteer tourism and voluntourism because they best fit my topic of analysis.

In accordance with Verardi (2013), the conception of voluntourism is the interplacement of tourism with volunteering, which makes possible for individuals to learn about the world, about other cultures and to get involved in local shortterm voluntary work. Brown (2005) explains volunteer tourism from the tour operators' perspective: voluntourism is a "type of tourism experience where a tour operator offers travelers an opportunity to participate in an optional excursion that has a volunteer component, as well as a cultural exchange with local people" (Brown 2005: 480). McGehee and Santos (2005) conceptualize volunteer tourism from the perspective of the volunteers. In another definition, volunteerism is "a specific type of sustained, planned, prosocial behavior that benefits strangers and occurs within an organizational setting” (Marta et al. 2006: 222).

A volunteer tourism excursion contains two main elements: tourism and volunteer services (Chen \& Chen 2011). Volunteer tourists pay for a trip to a location chosen by them, where they have the opportunity to be engaged in a meaningful experience such as helping local communities, conserving environment, or supporting a research (Polus \& Bidderb 2016). After Wearing (2001), volunteer tourism can be conceptualized as an alternative tourism and ecotourism. This kind of tourism has the potential to generate value changes and have positive influence both on volunteer tourists and the host community.

Volunteer tourism has its roots in Great Britain and Europe, from where it has spread all over Australia and the United States and is on its way to becoming popular in Asia and Africa as well (Wearing \& McGehee 2013). The main international events which made volunteer tourism to become widespread were the September $11^{\text {th }}$ incident and the Indonesian Tsunami. Nevertheless, for the increase in volunteer tourism, we may quote several other events as well such as the reduction of barriers to travel, the increased number of middle-class people, and their desire to experience unusual travel forms (Nestora et al. 2009, Otoo, 2013, Wearing \& McGehee 2013). Thus, Verardi (2013) contends that this kind of volunteering is a good opportunity for young people to get to know the world, themselves, and their role in the world.

The importance of volunteer tourism has grown since the 1970s, but the greatest increase was reached during the late $20^{\text {th }}$ century (Polus \& Bidderb 2016). Data indicate that 1.6 million people have participated in volunteer tourism projects 
worldwide, and they spent between $£ 832$ million and $£ 1.3$ billion per year (Wearing 2013). According to research on modern tourism, the modern tourist is attracted by heterogeneous spaces, where he/she can have a voice based on being, doing, touching, and seeing, and that is what volunteer tourism offers to them (Sin 2009).

Singh (2014) emphasized that volunteer tourism, like other forms of tourism, followed four phases of development. In the first phase, the negative impacts of voluntourism are emphasized. In the second phase of development, the accent is on exploring new host countries. In the third phase, studies investigate strategies in order to maximize positive impacts and to minimize negative impacts. The last phase of development emphasizes a multidisciplinary approach of voluntourism (Singh 2014).

Volunteer tourism is seen mostly as a form of "justice" or "goodwill" tourism, but there are also critics who question the effectiveness of volunteer tourism. Sin (2009) formulated the tensions and paradoxes in voluntourism. The author contends that in general volunteers are conscious toward some social issues, but after the volunteer tourist experience respondents are not necessarily able to be engaged with these social issues in future volunteering. This suggests that volunteer tourists are more passionate about traveling than are sensitive to social issues. Besides this, certain volunteer tourism programs may reinforce existing stereotypes (Sin 2009, Simpson 2004) and "may represent a form of neocolonialism or imperialism, in which volunteer tourists inadvertently reinforce the power inequalities between developed and developing countries" (Raymond \& Hall 2008: 531). Another tension discussed by Sin (2009) is that volunteer tourists tend to adopt a giving attitude, where the act of giving builds up the ego of the giver, making them feel superior to the receiver. Therefore, volunteer tourism always involves rich people to help poor people (Sin 2009). Raymond and Hall (2008) draw attention to the fact that volunteer tourism does not always result in cross-cultural understanding for the participants, and so it is the role of the sending organization to carefully manage the volunteer tourism programs (Raymond \& Hall 2008). After Guttentag (2011), volunteer tourism may cause dependency on the part of the host community, which can get used to relying on external resources, ignoring the self-sustainable development (Guttentag 2011).

The general perception of voluntourism is that it increases global citizenship in host and guest communities, improves cultural understanding, and contributes to peace in the world. However, it is important to mention the critics of this phenomenon, who emphasize that the interactions with the host community are not a guarantee for mutual respect, understanding, and long-term relationship (Singh 2014). The benefits of volunteer tourism are unquestionable, but there are worries as well, which could be eliminated by the organization volunteer tourism trips by apolitical organizations (Sin 2009, Guttentag 2011). 


\section{The particularities of voluntourism in Szeklerland (Romania)}

The practice of volunteering in Romania is a rather new phenomenon after December 1989. According to Romanian volunteer research (Voicu \& Voicu 2003a), in 1999, 10\% of the Romanians did voluntary work, in 2002 , $8 \%$ of the Romanian people were involved in volunteering, while in 2007 14\% was the rate of Romanian volunteers. With the exception of Russia and Ukraine, this is the lowest rate of volunteering among ex-communist countries.

After Voicu and Voicu (2009), there is a historical-social background which may explain the low rate of volunteering in Romania. Before 1945, the country was characterized as a mainly rural traditional country. In that time, volunteering at associations functioned in urban areas, and "the members of these associations were usually active in political parties, too..." (Voicu \& Voicu 2003a: 155). But in the first period of communism these people were imprisoned. During the communist period, the associations were controlled by the state, and it was forbidden for the civil society to function. In addition, the state introduced the compulsory "voluntary work", which concerned everyone from students up to laborers. Other characteristics of the country are the low level of higher educated people and the poor social capital, which were obstacles to the development of volunteering. The social network usually developed just inside the kinship, and as a result the society became fragmented and the level of trust between groups was low. So, all those conditions which are necessary for the development of volunteering were missing in Romania before 1989 (Voicu \& Voicu 2003a).

In Szeklerland, as part of Romania, the factors mentioned above were typical, too. It is also important to mention that not all Romanian tendencies about volunteering are relevant for Szeklerland. Historically, in this region, there was a feudal society where everyone had his own duty. The upper classes dealt with the main social issues, while the other members were only endurers of the measures taken. In the course of the history, in Szeklerland, almost all modernization endeavors were initiated from the central offices, often ignoring the local characteristics, which led to anti-modernization attitudes. Modernization was seen as an unauthorized intervention by the central power. These mechanisms were engrained so much in the Szekler people that, following the regime change, in the world of modernization and democracy, where citizens have the same rights, bottom-up initiatives did not start, and the proportion of civil organizations is still very low (Bárdi \& Pál 2016).

In fact, in this region, the culture of volunteering is a new phenomenon, which started to develop after December 1989. In these circumstances, volunteer tourism is even a somewhat new social practice. Until now, there was no research about volunteering or volunteer tourism in this region, and not all the data 
about Romanian volunteering are relevant for Szeklerland because of the above mentioned peculiarities.

\section{The voluntourist profile}

Volunteer tourists are that kind of people who invest their time, budget, and energy in a destination far from their home to acquire various forms of experiences (Chen \& Chen 2011). Many studies (e.g. Barron \& Knoll 2009, Brown \& Morrison 2003) indicate that most of the volunteers are aged between 20 and 29 years. Volunteering is a more common activity among women. The explanation can be (e.g. Andreu et al. 2005) that they have a stronger motivation to travel, relax, explore, and socialize. The educational level is a main factor in the motivation to travel: for volunteer tourists with higher educational background, it is important to seek knowledge and to get to know new places and peoples (Otoo 2013).

The duration of volunteer projects may range from one week to over a year in length. Volunteer tourists who choose a project with over a year in duration are more altruistic than those who opt for a shorter time. Volunteer tourists who stay for a longer time in the host community tend to consider themselves volunteers and not tourists (Otoo 2013). The main factors which attract volunteer tourists to choose a destination are the culture and the people, which are followed by the volunteer opportunity, political climate, geography, and touristic attractions (Otoo 2013).

Countries which produce volunteer tourists are the same countries where the gap year has become popular such as Canada, the Unites States, Australia, New Zealand, and some Western European nations. For charity organizations and NGOs, the key target group is that of the gap-year volunteer tourists because they are young and are looking for novelty and authentic exotic places (Lyons et al. 2012).

Callanan and Thomas (2005) define three types of volunteer tourists based on six criteria (destination; duration of project; focus of experience, i.e. selfinterest versus altruistic; qualifications; active versus passive participation; level of contribution to the local community): 1) shallow volunteer tourists are sensation-seeking volunteers who have mostly personal interests, 2) intermediate volunteer tourists, and 3) deep volunteer tourists, who tend to think more about the community (see also Wearing \& McGehee 2013: 123).

\section{Volunteer tourist motivation}

In this chapter, my aim is to resume some of the results of the studies about volunteer motivations. "Motivations are the essential reasons for a particular traveling behavior and play a vital role in understanding the decision-making 
process of tourists as well as assessing the subsequent satisfaction of tourists' expectation" (Otoo 2013: 2). The motivation of individual volunteer tourists is very complex, and it depends on demographic variables, but the most common motivations are the desire for authenticity, social integration, intense interaction with locals, enhanced cultural appreciation, and intercultural exchange (Kontogeorgopoulos 2017). Wearing et al. (2008) contend that individuals who practice volunteer tourism transform their leisure into self-exploration. Volunteer tourism is a leisure activity which helps individuals to have a meaningful experience and meaningful life, to discover and understand themselves, which is impossible to get in daily routine (Chen \& Chen 2011).

Usually, volunteers are altruistically motivated, but there are also egoistic motives - so, volunteer tourists usually have a double motivation: they want to do something beneficial for the host community and also want to reach personal development (Polus \& Bidderb 2016). In accordance with Wearing (2001), volunteer tourists' motivation includes altruism, travel, adventure, personal growth, cultural exchange, learning, professional development, etc. Others claim that volunteers travel because of four reasons: cultural immersion, altruism (to give back), camaraderie, and family (Brown 2005). After Caissie and Halpenny (2003), the focus is more on the self than on altruistic reasons, and the expectations of the trips also include relaxation and stimulation.

In the case of students, the motivations behind volunteer tourism are personal development and academic achievement (Chen \& Chen 2011). Volunteer tourists use volunteer placement to improve their skills, which can be transferred to the labor market, others to get to know new cultures and acquire practical skills "during and after their university education" (Otoo 2013: 2). In the research of Wearing and McGehee (2013), the younger volunteer tourists' primary motivation is self-interest, while older volunteer tourists (aged between 40 and 70 years) are motivated by cultural immersion, seeking camaraderie, giving something back, and family bonding.

In the literature, there are many classifications of the volunteer tourists' motivational factors. Based on these, McGehee et al. (2009) identify three volunteer tourist types: 1) the Vanguards are young people - they form the most motivated group, are interested in skill-building, experience physically and mentally intense volunteer tourism; 2) the Pragmatists are made up of a middleaged group, who are mostly motivated by the idea of developing a relationship with members of the host community; 3) the Questers are the oldest group although they cannot name their motivation, it is getting close to altruism (see also Wearing and McGehee 2013: 122).

Rehberg (2005) uses also three categories in order to classify volunteer tourists based on their motivations: 1) the achievement of something positive: this volunteer tourist focuses more on the ethical values and consideration; 2) quest 
for the new: this volunteer tourist focuses more on new experiences, culture, and friends; 3) quest for oneself: this volunteer tourist focuses more on self-serving goals and on career, their professional or academic field. In their research, Chen and Chen (2011) classified the international volunteer tourists' motivations into three categories: personal, interpersonal, and other factors. Personal factors are the authentic experience of the trip, interest in traveling, challenges, and stimulation. Interpersonal factors are desire to help, interaction with locals/ cultures, encouragement from others, and enhancing relationships.

\section{Methodology}

Similarly to previous voluntourism studies, I used a qualitative method to get an answer to the question why international volunteer tourists come to Szeklerland. As in Romania volunteering is a kind of new phenomenon in this region, we are in need to do explorative research. For this purpose, qualitative methods are particularly appropriate, and so I relied on interviewing in order to explore the phenomenon of international volunteering in Szeklerland. The study's aim is to investigate the key motivations of the participants who have joined international volunteer tourism trips in Romania.

To conduct the research, I contacted the Care2Travel association from Miercurea Ciuc because this is the association which receives the largest number of international volunteers in the region. I interviewed 11 international volunteers during the summer of 2016.

\section{The Care2Travel association}

The study unit of my analysis, i.e. Association Care2Travel, was set up in 2011. The main actor of this Association is a woman from England. She first came in Romania as a volunteer tourist in 2009. After many experiences as a volunteer and volunteer coordinator in Romania, she decided with two colleagues to set up a non-governmental organization in Harghita County in order to receive foreign volunteers. They identified two social problems they intended to tackle: an underdeveloped volunteering community in Transylvania and a struggling welfare state with many disadvantaged communities operating on the margins of society. The Association's aim is to support and promote responsible volunteering, break down barriers, and establish the environment where volunteering can get involved (see: www.care2travel.org).

Today, the Association promotes volunteering service combined with tourism services. Indeed, it is a host association in receiving foreign volunteers in Szeklerland and transferring them to volunteer placements in the region. The Association 
offers individual and pair volunteering services such as English teaching (termtime only), after-school support (term-time only), childcare (available throughout the year), special needs care (available throughout the year), agriculture (available throughout the year), NGO support (available throughout the year), and 2-Day Volunteering Taster. It has also group volunteering services such as organizing and managing English summer camps with the local volunteers. The touristic activities offer exciting adventure tours, such as cycle tours, hiking tours, winter tours, or tailor-made tours, with the chance to explore Romania (see: www.care2travel.org).

The Association hosts approximately 200 volunteer tourists a year. July and August are usually the busiest months when the Association hosts between 10 and 20 individual volunteers per week. But there are programs for volunteer groups, too, when the association hosts groups; e.g. a group of 49 stayed for a week. The winter season, December-February, is quieter. In that period, the Association hosts between 2 and 6 volunteers per week (based on an interview with the Association's director).

The Care2Travel association has a 4-member permanent staff. The director and the volunteer coordinator of the Association select the volunteering activities after careful consideration and discussions with their local partners. They are continuously establishing new volunteer placements in the community. Placing volunteers depends on a variety of factors. The first step is when the volunteer chooses from the website the placement she/he is most interested in. After that, the director of the Association and the volunteer coordinator examine the motivations, the professional experiences, and the planned time of the volunteer and compare these with the volunteer placements. Finally, they place the volunteer where she/he can help the most. The aim is to make a good match (based on the director's interview), making use of all the information that the Association is given about the volunteer and with input from the local partners.

The Association has several international partners. The most significant one is from New Zealand, the International Volunteering Headquarters, which markets the placements of Care2Travel for individual volunteers all around the world. Other partners are the University of Hull (United Kingdom), the World Challenge (United Kingdom), and the International Volunteering Service Belgium, from where they receive student volunteers (based on interviews with the Director).

\section{Research findings}

\section{The volunteer tourists' profiles}

The international volunteers were randomly selected for the study. There were lists in every week with the name of the volunteer tourists who were volunteering 
in Szeklerland in the period of the research, the summer of 2016. I also was in connection with the Association's director and volunteer coordinator, who helped me to meet the international volunteers. I interviewed only those who had already been volunteering for at least one week in Szeklerland.

Table 1. Characteristics of the international volunteer tourists

\begin{tabular}{lccccc}
\hline ID & Age & Gender & Country of origin & Occupation & Duration of stay \\
\hline M1 & 21 & Male & Pakistan (Pakistani) & Student & 5 weeks \\
\hline M2 & 30 & Male & Singapore & Student & 3 weeks \\
\hline F1 & 38 & Female & England & Nurse & 2 weeks \\
\hline F2 & 21 & Female & England & Student & 1 week \\
\hline F3 & 22 & Female & Australia & Gap year & 2 weeks \\
\hline F4 & 19 & Female & Australia & Student & 4 weeks \\
\hline F5 & 24 & Female & USA (Colorado) & Gap year & 4 weeks \\
\hline F6 & 54 & Female & USA (Florida) & Teacher in primary & 4 weeks \\
& & & school & \\
\hline F7 & 22 & Female & Switzerland & Childrearing & 4 weeks \\
\hline F8 & 22 & Female & Mauritius & Student & 4 weeks \\
\hline M3 & 25 & Male & USA & Student & 2 weeks \\
\hline
\end{tabular}

Source: author's own editing

As seen from the table above, the majority of the respondents came from developed countries such as the U.S.A., the U.K., Australia, Switzerland, or Singapore. Two of them were from developing countries such as Afghanistan and Mauritius. Some of them had already been international volunteers more than once, but for most of them this trip was the first international volunteer experience.

\section{Socio-demographic characteristics}

A detailed description of the volunteers' profile was crucial for the interpretation and understanding of the motivations for volunteering in Romania (Szeklerland). The international tourists who contributed to this study were three males and eight females, most of them being single. The age of the respondents ranged from 19 to 54 years, but the age around 20 years dominated the age category, and only one respondent was 54 years old. Most of the respondents were educated at the tertiary level or had been studying at a university; only one respondent had secondary-level education. Most of them came from a well-situated family in terms of social status such as ambassador's son, IT manager's daughter, doctor's daughter, lawyer's daughter, and only a few mentioned that her/his father was a mechanic, without qualification or was retired. Almost all of the respondents had siblings, only one was the single child in the family. All the international volunteers were first-time visitors to Romania. 


\section{Motivations for volunteering in Szeklerland}

During participant interviews, the questions were divided into five main sections: definitions of volunteering, motivations, experiences, costs and benefits, and future plans. In this paper, I focus only on the motivations of international volunteers. Following the analysis of the interviews, the following themes emerged:

\section{Increasing professional experience}

One of the most frequently mentioned reasons which attract international volunteer tourists to join this trip was to get professional experiences which in the future can benefit them on the labor market.

Just because I worked at human development field. A lot of people didn't study attachment, you know, child attachment, but with Romanian orphans it was much worse. So I thought that this would be a good place for me to learn about my field [...], and when I go back, and I am applying for a job, people would understand what I was doing. It is easier to relate with my job. (F5) [...], I said that I have only two more years to teach in America before I retire. I was thinking that maybe after retiring I would go to teach overseas in international school. I just decided that in my summer vacation which is June-July and a little bit of August, I would go to other countries to volunteer and get experience. So, when I want to have a job, I will have experience in different countries. (F6)

There was also a respondent who set up an organization and wanted to learn how to manage it; so, to acquire experiences, he applied for volunteering abroad. He explained that:

We made our organization at home, in Pakistan. I have a vision in my mind. When I go back, I want to pursuit professionally, make a proper organization, then people can come and volunteer. For example, like Care2Travel. So, I want to do something in that line where I can learn those kind of skills. I was looking up and I saw IVHQ and NGO support program. This was the first line, the start. This is the program that I want to do [...].(M1)

\section{Interest in travel}

Another frequent motivation of international volunteers was to experience the country. None of the participants had ever been in Romania before, wherefore 
volunteering was an opportunity for them to embark on an adventure in an entirely foreign country.

[...] I can also experience the country. I heard good things about Romanian Carpathians. It is a really nice place to be in. (F5)

Because it is a very pretty place. I want to explore it. And this is a different experience from the family trip. It is a typical country which is different with challenges. (F2)

[...] this would be a good chance to find out and also to do some travel. (F6)

\section{Make a difference}

Some interviewees expressed a desire to help, to make a difference. They expressed that there are happening sad things in the world, which are broadcasted through the media; so, certain well-off people feel the necessity to do something for the world.

And I want to volunteer because I want to do something... I just felt sad about things happening in the world... and I can do something, too, I can go volunteering, so I tried volunteering. I thought whatever I can do will be a better practice than sitting in my apartment. (F7)

I was after my exams and I would have five weeks' holiday, I really wanted to do something. I worked before, so I saved some money. I wanted to volunteer overseas. (F4)

[...] because I am quite privileged, and I thought it is good sometimes to do things and give back to the society in the way you are comfortable whit it. (F3)

\section{Personal growth}

In most of the cases, the major motivation for international volunteering was the gaining of professional experiences combined with the importance of personal development. Through volunteering, one can develop his/her personality, beliefs, and their skills.

What really, really encouraged me was that I wanted to do something different during the holidays. As a law student... as I know every law student went for an internship, for a placement in a law firm and actually got [it] for a month, but I wanted to do something else because I strongly believe that volunteering makes you grow, just simply doing what is expected to do. (F8) 


\section{Interaction with locals/culture}

Another frequently mentioned motivation of the volunteer tourists' trips is the desire for interaction with new cultures and communities (Wearing \& McGehee 2013). Volunteer tourists want to be in interaction with local people and to get to know a new culture. For example, before coming in Romania, F1 met Romanian people in her country, which was a pleasant experience for her. Therefore, she wanted to get to know this nationality more closely.

In England, there are many Romanian people, and I saw in children's home and also in the street homeless Romanians. All are especially nice, like very natural people, at least those with whom I talked. It is a nice nation. They are polite and friendly. Because I saw so many in London, I wanted to know why they want to come here from there. (F1)

\section{Strengthen relations, identity}

Some volunteer tourists use the opportunity of the volunteer tourism to strengthen their relationship with their families, relatives, or friends. In this research, one of the interviewees went on this volunteer trip to be with their friends who are also volunteering.

Honestly he [my friend] chose Romania, and I just followed him. [...] I told him "You just choose a place, and I [will] likely go there with you." Instead, we had chosen a place together, where he could go and where you don't waste your time. (M2)

Another participant wanted to combine the international volunteering trip with visiting their relatives who are living far from them and also to learn and practice their mother tongue, the Hungarian language, because at home she just learnt the English.

Because they speak Hungarian. I want to know Hungarian. I have some relatives at Cluj-Napoca. I visited them, and they got me here, so they drew me here. It was good to see them as well [...]. (F3)

\section{Time and money}

Most of the interviewees were on a university holiday, some of them were taking a break from school or work, and they wanted to use this period for something useful for themselves and for the society. Every participant had to pay for this 
volunteering opportunity; so, even if they did not state it explicitly, all the interviewees had to have time and money to participate.

None of the interviewees had been in Romania before. For some of them, it was the first time to be in Eastern Europe, too. There were respondents who came to Romania accidentally, who did not plan on choosing Romania as a volunteer placement. For example, M1 wanted to go to Vietnam, but he could not get the visa, and so in the last minute the volunteer tourism organization recommended for him a placement in Romania, and he accepted the offer. Another volunteer tourist wanted to go to teach in an Eastern European country, and the only teaching offer during the summer of 2016 was in Romania. There were also volunteer tourists who chose Romania as a volunteer tourist placement because nowadays Romania seems to be a safe country to travel to. Only just a few of them had the desire to know the Romanian landscape and culture. Most of them had not heard about Romania before, but there were some participants who knew a little bit about the country, mostly in the sense of stereotypes such as Romania is a poor country, the beauty of the Romanian Carpathians, good universities at affordable prices, etc.

\section{Discussion and conclusions}

The aim of this study was to present the case of a non-governmental organization in Szeklerland, which receives and distributes international volunteers in different volunteer placements in Szeklerland. Additionally, I wanted to present the international volunteers' motivations for participating in this program and the reasons for choosing Romania as volunteer tourist placement, as much as Romania is an Eastern European post-communist country which is barely visible on the map of volunteering. Until 1989, volunteering had been a missing link in Eastern Europe. In the 2000s, too, volunteering continued to be a new phenomenon and a "missing link on the road to European integration" (Voicu and Voicu 2003b: 15).

During the 2000s, local volunteering in Szeklerland started to become visible, although it is still in an embryonic state. Cohorts born in the late 1980s, who were socialized in the transition period, are more open-minded towards volunteering (see Fényes 2015), but the phenomenon of international volunteering is still a new one to the society of Szeklerland. This can be captured through the fact that the very initiative to establish an international volunteer organization in Szeklerland came from a citizen of English nationality. Her organization offers volunteer tourism services and receives the largest number of international volunteers in the region.

As stated in the article, volunteer tourism is an emerging field of the tourism industry both in developing and developed societies (Wearing 2013). This activity is typically regarded as a practice of privileged Western people who visit 
exotic third-world societies (Verardi 2013), and the beneficiaries of voluntourism are supposed to be both tourists and locals. The tourists satisfy their need to travel and to make something different during the holiday. This type of excursion guarantees authentic experiences in places where tourism is not so developed such as in protected rural areas or remote villages (Chen \& Chen 2011).

Volunteer tourism is a new phenomenon in Szeklerland. Until now, only one organization has been offering volunteer tourism services, which is managed by an English woman who comes from a society where volunteering is at a developed level and where volunteer tourism has taken roots. This Association's aim is to manage a responsible volunteer tourism: it tries to realize projects which satisfy volunteer tourists' desires and is also beneficial for the local community. The research has revealed that this kind of trip is not a new phenomenon for volunteer tourists, while for the local people the presence of international volunteers is something new, and they are not yet ready to receive them. Volunteer tourism in Szeklerland is led by the Care2Travel association, which can influence the international voluntouristic behavior and can contribute to local people's openmindedness towards international volunteers. For example, with partners from the UK, they attract several English students to the region and place them to help English teachers in teaching English for children.

\section{References}

Andreu, Luisa, Kozac, Metin, Avci, Nilgun, Cifter, Nurten. 2005. Market Segmentation by Motivations to Travel: British Tourists Visiting Turkey. Journal of Travel and Tourism Marketing 19(1): 1-14.

Ashley, Caroline, Roe, Dilys, Goodwin, Harold. 2001. Pro-Poor Tourism Strategies: Making Tourism Work for the Poor. Pro-Poor Tourism Report No. 1. Nottingham: Overseas Development Institute.

Barron, Paul, Knoll, Amanda. 2009. Towards an Understanding of Volunteer Motivations: A Case Study of Volunteers at Edinburgh's Fringe Sunday. In: J. Allen (ed.), The International Event Management Summit: Conference Proceedings and Book of Abstracts. Sydney: Australian Centre for Event Management and the University of Technology. 87-97.

Bárdi, Nándor, Pál, Judit. 2016. Székelyföld története. III. kötet. Székelyudvarhely: MTA BTK-EME-HRM.

Brown, Sally. 2005. Travelling with a Purpose: Understanding the Motives and Benefits of Volunteer Vacations. Current Issues in Tourism 8(6): 479-496.

Brown, Sally, Morrison, Alastair. M. 2003. Expanding Volunteer Vacation Participation: An Exploratory Study on the Mini-Mission Concept. Tourism Recreation Research 28(3): 73-82. 
Caissie, Linda. T., Halpenny, Elizabeth. A. 2003. Volunteering for Nature: Motivations for Participating in a Biodiversity Conservation Volunteer Program. World Leisure Journal 45(2): 38-50.

Callanan, Michelle, Thomas, Sarah. 2005. Volunteer Tourism: Deconstructing Volunteer Activities within a Dynamic Environment. In: M. Novelli (ed.), Niche Tourism: Contemporary Issues, Trends and Cases. Oxford: ButterworthHeinemann. 183-200.

Chen, Li-Ju, Chen, Joseph S. 2011. The Motivations and Expectations of International Volunteer Tourists: A Case Study of "Chinese Village Traditions". Tourism Management 32: 435-442.

Ellis, Claire. 2003. Participatory Environmental Research in Tourism: A Global View. Tourism Recreation Research 28(3): 45-55.

Fényes, Hajnalka. 2015. Önkéntesség és új típusú önkéntesség a felsőoktatási hallgatók körében. Debrecen: Debrecen University Press.

Guttentag, Daniel. 2011. Volunteer Tourism. As Good as It Seems? Tourism Recreation Research 36(1): 69-74.

Hall, Michael C. 2007. Pro-Poor Tourism: Who Benefits? NY: Channel View.

Kass, Jessye. 2013. Voluntourism. Exploring Ethical Challenges and Critical Tensions within the Pay-to-Volunteer Industry. (Senior Thesis). Waltham, MA: Brandeis University. (https://bir.brandeis.edu/bitstream/ handle/10192/25162/ KassThesis2013.pdf - last visit on: November 19, 2016).

Kontogeorgopoulos, Nick. 2017. Forays into the Backstage: Volunteer Tourism and the Pursuit of Object Authenticity. Journal of Tourism and Cultural Change 15(5): 1-21.

Lyons, Kevin, Hanle, Joanne, Wearing, Stephen, Neil, John. 2012. Gap Year Volunteer Tourism. Myths of Global Citizenship? Annals of Tourism Research 39(1): 361-378.

Marta, Elena, Guglielmetti, Chiara, Pozzi, Maura. 2006. Volunteerism during Young Adulthood: An Italian Investigation into Motivational Patterns. Voluntas 17(3): 221-232.

McGehee, Nancy G., Santos, Almeida, Carla. 2005. Social Change, Discourse, and Volunteer Tourism. Annals of Tourism Research 32(3): 760-779.

McGehee, Nancy. G., Lee, Seungwoo, Clemmons, David. 2009. The Mystery of the Voluntourist: Utilizing Pearce and Lee's Travel Career Pattern Model to Examine Motivations, Typologies, and Preferences of Potential Voluntourists. USA: Greater Western Chapter of the Travel and Tourism Research Association. March 17-20.

McMillion, Bill, Cutchins, Doug, Geissinger, Anne. 2006. Volunteer Vacations ( $9^{\text {th }}$ ed.). Chicago: Chicago Review Press.

Otoo, Felix Elvis. 2013. Motivations of American Volunteer Tourists to Ghana. African Journal of Hospitality, Tourism and Leisure 2(4): 1-12. 
Polus, Reni Cacillia, Bidderb, Christy. 2016. Volunteer Tourists' Motivation and Satisfaction: A Case of Batu Puteh Village Kinabatangan Borneo. Procedia Social and Behavioral Sciences 224: 308-316.

Raymond, Eliza, Marguerite, Hall, C. Michael. 2008. The Development of Cross-Cultural (Mis)understanding through Volunteer Tourism. Journal of Sustainable Tourism 16(5): 530-543.

Rehberg, Walter. 2005. Altruistic Individualists: Motivations for International Volunteering among Young Adults in Switzerland. Voluntas: International Journal of Voluntary and Nonprofit Organizations 16(2): 109-122.

Simpson, Katt. 2004. 'Doing Development': The Gap Year, Volunteer-Tourists and a Popular Practice of Development. Journal of International Development 16(5): 681-692.

Sin, Harng Luh. 2009. Volunteer Tourism-“Involve Me and I Will Learn”? Annals of Tourism Research 36(3): 480-501.

Singh, Ranbir. 2014. Volunteer Tourism and Host Community. International Journal of Scientific Research and Management (IJSRM) 2(10): 1480-1487.

Singh, Tej Vir. 2002. Altruistic Tourism: Another Shade of Sustainable Tourism. The Case of Kanda Community. Tourism. Tourism: An International Interdisciplinary Journal 50(4): 361-370.

Silló, Ágota. 2016. The Development of Volunteering in Post-Communist Societies. A Review. Acta Universitatis Sapientiae, Social Analysis 6(1): 93110.

Verardi, Cassandra. 2013. Perception of Voluntourism. Ottawa: Carleton University. (Thesis). (https://curve.carleton.ca/system/files/etd/9555f4e4156e-471a-a60b-b8267f599005/etd_pdf/37fac09309ec38cf36a562712b9ff7a1/ verardi-perceptionsofvoluntourism.pdf - last visit on: November 19, 2016).

Voicu, Mălina, Voicu, Bogdan. 2003a. Volunteering in Romania. A Rara Avis. In: P. Dekker, L. Halman (eds.), The Values of Volunteering. Cross-Cultural Perspectives. New York: Kluwer Academic/Plenum Publishers. 143-159. 2003b. Volunteering in Eastern Europe: One of the Missing Links? In: B. Voicu, H. Rusu (eds.), Globalization, Integration, and Social Development in Central and Eastern Europe. Sibiu: Psihomedia. 57-66.

Wearing, Stephen. 2001. Volunteer Tourism: Experiences That Make a Difference. Wallingford: CABI Publishing.

Wearing, Stephen, McGehee, Nancy Gard. 2013. Volunteer Tourism: A Review. Tourism Management 38: 120-130. 